
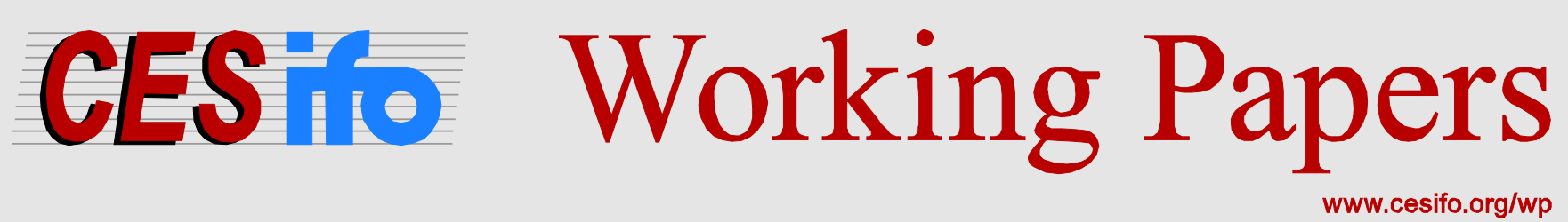

\title{
Government Decentralization as a Commitment
}

\author{
Mark Gradstein
}

CESIFO WORKING PAPER NO. 4809

CATEGORY 1: Public FinANCE

MAY 2014

Presented at CESifo Area Conference on Public Sector Economics, April 2014

An electronic version of the paper may be downloaded

- from the SSRN website:

- from the RePEc website:

- from the CESifo website:

www.SSRN.com

Www.RePEc.org

www.CESifo-group.org/wp

\section{CESifo}




\title{
Government Decentralization as a Commitment
}

\begin{abstract}
In the past several decades, many countries, among them non-democratic, chose to decentralize their governments. Building on insights provided by the "second generation" wave of research on fiscal federalism, this paper proposes a unified model to account for this. The idea is that decentralization serves as a commitment device to ensure that ex post chose policies will reflect regional preferences, thereby boosting individual productive effort incentives. This theory may explain the decentralization process in China in 1980-1990s, as well as the fact that government decentralization is generally more prevalent in democracies.
\end{abstract}

JEL-Code: H100.

Keywords: federalism, regional decentralization, non-democracies.

Mark Gradstein

Ben-Gurion University of the Negev

Beer-Sheva / Israel

grade@bgu.ac.il

March 2014 


\section{Introduction}

Tradeoffs involving fiscal decentralization versus a centralized government structure have been extensively studied since the seminal work of Oates, 1972, and Tiebout, 1956. In its beginning, literature tended to view developed countries as its paradigm, implicitly assuming a democratic country as its focus. Yet, in the last several decades many developing countries have decentralized with explicit objective of improving service delivery (World Development Report, 2004), and it appears that that they have grappled with similar issues (as well as with additional ones). Consequently, more recent work addresses government decentralization in the context of development (Bardhan, 2002). While many of the countries that have pursued decentralization are democracies, some are not. A good example of decentralization in a non-democratic setting is provided by the recent history of China, where local decentralization, at the village level and then at the province level, started taking place in 1980s, incidentally, prior to the introduction of elections there. Consequently, local administrative units have obtained much autonomy in policy making. Scholars suggest that this process enhanced efficiency and might have well been responsible for China's spectacular economic growth in recent decades (Qian and Weingast, 1997). Insights from China's decentralization process have recently led the theory of fiscal federalism to be applied to non-democratic settings as well (e.g., Weingast, 1997).

When looking across countries, it appears that the degree of decentralization varies, so that in particular democracies are much more decentralized than non-democracies. For 
example, a simple correlation between the share of sub-national government spending and democracy measures, such as Gastil's index, is around 0.50. ${ }^{1}$ Earlier research has found that democratic governance remains a strong predictor of decentralization also after including controls, such as countries' geographic and ethnolinguistic characteristics (Panizza, 1999).

In this paper, viewing China's 1980s' move toward decentralization as a prototypical case, we address tradeoffs involved in such a transition both in democracies and in nondemocracies. In particular, one question we ask is what makes voluntary devolution of centralized power by ruling elites possible. Enriching the standard fiscal federalism framework and building upon the insights of the "second generation" theories of fiscal federalism (Qian and Weingast, 1997), we argue that decentralization is a commitment device. More specifically, in our context, this commitment device ensures that ultimately chosen equilibrium policies better reflect individual preferences. As these preferences are assumed complementary to productive efforts, this, in turn, ensures that a larger amount of such efforts will be generated. In this view, therefore, decentralization is a way to ultimately enhance efficiency by partially solving the holdup problem. This rationalizes a voluntary devolution of power by the ruler under decentralization. We then turn to a democratic setting. The same tradeoff is identified there too; in fact, it may even be stronger in democracies, implying that fiscal decentralization should on average be more common there.

\footnotetext{
${ }^{1}$ See De Mello and Barenstein, 2001.
} 
It should be noted that the mechanism identified here is different from and complementary to the agency view of decentralization. The agency view focuses on the ability (or lack thereof) of decentralized decision making to monitor local politicians through local elections, and there is a debate as to its efficiency in doing so (Keefer, 2007, Khemani, 2007). A theoretical perspective on political agency and its empirical validity in the context of development have been developed in several papers elsewhere (Albornoz and Cabrales, 2013, Bardhan and Mookherjee, 2005, 2006, Besley, 2006, Besley et al., 2005, Joanis, 2013, Seabright, 1996). While both mechanisms can be used to understand, for example, the impetus and the rationale behind China's decentralization reforms of the 1980s, the agency approach emphasizes the political and accountability portion of it, whereas the mechanism exhibited here puts squared emphasis on the effect of government decentralization on tailoring policies to local preferences and is, therefore, more in line with the traditional fiscal federalism approach (Oates, 1972). It should be noted that there exists a vast literature that explores the pros and cons of decentralization from various perspectives and, in particular, detrimental potential of decentralization has been pointed out (e.g., Bardan and Mookherjee, 2006, Cai and Treisman, 2006, among others). ${ }^{2}$ This paper aims, therefore, to contribute to this literature by clearly laying out the commitment incentives to pursue decentralization in democracies and, more importantly, in non-democracies. This unified framework should be

\footnotetext{
${ }^{2}$ And the survey in Martinez-Vazquez and McNab, 2003, illustrates the difficulty in signing off whether or not decentralization is effective in leading to faster growth.
} 
helpful in interpreting decentralization processes that have taken place around the world in past decades.

Hatfield and Padró i Miquel, 2012, is another important related work. There, the politically determined degree of centralization balances redistribution motives with the desire to commit to policies that prevent capital flight. Here, instead, we abstract from capital mobility, and decentralization serves a different purpose than in Hatfield and Padró i Miquel, 2012. Also, our model adds insights as to the institutional comparisons of decentralization incentives.

In addition to the literature on fiscal decentralization, the paper is related to recent work on the determinants of democratization. Part of this work (Acemoglu and Robinson, 2008, Bertocchi and Spagat, 2001, Gradstein, 2007, 2008) views democratization as a commitment mechanism employed by ruling elites in order to advance own goals. ${ }^{3}$ In particular, in Gradstein, 2007, democratization is pursued by ruling elites to ensure that it can lead to high quality institutional choices, while inducing higher investment and growth. This paper can be viewed as an extension of this line of thought, suggesting that, more generally, devolution of power can be viewed as useful by political leaders or ruling elites, out of strategic motives. The common thread here is that the choice of a governance model serves as a commitment. Comparison of decentralization incentives in democracies versus non-

\footnotetext{
${ }^{3}$ Sometimes this is done under threat - of insurgency, rioting, etc., see Cervellati et al., 2008, and references therein. This paper is more related to the part of the literature where democratization occurs peacefully.
} 
democracies is another novel contribution of this paper, which has clear empirical implications, discussed later in the paper.

The rest of the paper proceeds as follows. The next section describes the model. Then Section 3 explores policy choices undertaken under the assumption that policies can be directly committed to. Section 4 contains the main analysis, whereby a centralization mode is chosen in the first, constitutional stage; both democracies and non-democracies are considered in this regard, and comparison among them is made; and Section 5 concludes.

\section{Basic framework}

Consider an economy that is populated by a measure one of individuals, indexed $i$, residing in two regions. The economy operates over a single period. ${ }^{4}$ All region's residents are identical and are characterized by their ideal local policies (e.g., in the areas of health, education, or infrastructure), located in the unit interval. In particular, we assume for simplicity that the individuals are organized into two symmetric regional groups of identical size, $1 \frac{1}{2}$, indexed $j$, and their respective ideal policies are assumed $\pi_{1}=0, \pi_{2}=1$.

\footnotetext{
${ }^{4}$ An interesting two period extension is briefly discussed below.
} 
We let $0 \leq \mathrm{p}_{\mathrm{j}} \leq 1, \mathrm{j}=1,2$, denote actual policy choices in a region; $\delta_{\mathrm{j}}=\left|\pi_{\mathrm{j}}-\mathrm{p}_{\mathrm{j}}\right|$ the distance between ideal and actual policies; and $\Delta=\left|\mathrm{p}_{1}-\mathrm{p}_{2}\right|$ the distance between regional policies. The individuals choose productive effort $e_{i}$, incurring a cost of $e_{i}^{2} / 2$. Income $y_{i j}$, is produced using productive effort:

$$
\mathrm{y}_{\mathrm{i}}=\mathrm{e}_{\mathrm{i}}
$$

Income is taxed at an exogenous rate $0<\mathrm{t}<1$, and the proceeds are used to produce a national public good, G. ${ }^{5}$ Net income, equivalent to private consumption, therefore, is (1-t) $y_{i}$, and the production function of the public good is assumed to depend on two components. One is the amount of tax revenue, $\mathrm{R}=\mathrm{t} \int y_{i} d i$. The second component is the productivity of public spending. We assume that the latter is adversely affected by the distance between the regional policies, $\Delta$. It then follows that the production function of the public good can be written as follows:

$$
\mathrm{G}=\mathrm{R} g(\Delta), \mathrm{g}, \mathrm{g} "<0
$$

This specification implies that regional policy polarization is detrimental for the production of the national public good; in contrast, regional policy coordination boosts it up. It, therefore, represents the spillover effect entailed in regional policy choices. While such

\footnotetext{
${ }^{5}$ Assuming taxation exogenous enables us focusing on local policies' determination.
} 
spillover effects are standard in the fiscal federalism literature (Oates, 1972), they are typically modelled by having them enter individual utilities directly. Here, in contrast, they affect utilities indirectly, via the production of national public goods. ${ }^{6}$

Private consumption is derived from net income, and its utility depends, in addition to that income, on the preference distance between ideal and actually implemented policies, so that, in particular, the larger the distance the smaller the marginal utility from private consumption, and we assume:

$$
\mathrm{u}_{\mathrm{j}}\left(\mathrm{c}_{\mathrm{i}}\right)=\mathrm{c}_{\mathrm{i}} \mathrm{f}\left(\delta_{\mathrm{j}}\right)=(1-\mathrm{t}) \mathrm{y}_{\mathrm{i}} \mathrm{f}\left(\delta_{\mathrm{j}}\right)=(1-\mathrm{t}) \mathrm{e}_{\mathrm{i}} \mathrm{f}\left(\delta_{\mathrm{j}}\right), \mathrm{f}^{\prime}, \mathrm{f}^{\prime \prime}<0
$$

This assumption is designed to capture the idea that bringing local policies closer to the people generates effort incentives.

It will be useful to normalize both $g$ and $f$, so that $g(0)=f(0)=1, f(1)=g(1)=0$. These normalizations save notation and do not affect substantive analysis.

The individual utility is a function of the cost of effort, utility from private consumption, and the public good, and we write:

\footnotetext{
${ }^{6}$ An alternative, but equivalent for the analysis assumption, would be that the individuals derive utilities from lower policy polarization, as well as from the amount of tax revenues used to provide national public goods, whereby these are complementary to each other; we favor the proposed modelling because of its simplicity.
} 


$$
\mathrm{U}_{\mathrm{ij}}=-\mathrm{e}_{\mathrm{i}}^{2} / 2+\mathrm{u}_{\mathrm{j}}\left(\mathrm{c}_{\mathrm{i}}\right)+\mathrm{G}=-\mathrm{e}_{\mathrm{i}}^{2} / 2+(1-\mathrm{t}) \mathrm{e}_{\mathrm{i}} \mathrm{f}\left(\delta_{\mathrm{j}}\right)+\mathrm{t} \int y_{i} d i \mathrm{~g}(\Delta)
$$

Under non-democracy, our first main focus, there is a ruler originating from either region 1 or region 2 (we will assume the former for concreteness). The ruler then decides whether policies are to be determined centrally or in a decentralized manner. Upon the determination of the centralization regime, the individuals select efforts. Then, policies are determined according to the regime in place: under centralization, the ruler sets the policies in both regions, whereas under decentralization each region's residents select policies, independently of each other. Income is produced, taxed, and government revenues derived that are used to provide the public good. Under democracy, individuals first decide, by majority vote, the centralization regime, then in the case centralization is selected, the policy maker is chosen at random. The rest then proceeds as in above. Our interest will be in exploring the subgame perfect equilibrium of this game.

Note that we assume away ruler's possible expropriation under non-democracy. This is done primarily for simplicity, and introducing expropriation of a part of tax revenues would not change much of a substance. As will be seen below, what matters for our result is a policymaker's interest in generating tax revenues, their specific use being immaterial for that matter. An important assumption is that the decision on decentralization mode is more fundamental than subsequent policy choices; consequently, a decision on such a mode constitutes a commitment. The reason for this is that hierarchical structure of the government, if not enshrined in a country's constitution, such as under federal arrangements, 
at least requires a level of institutional framework (such as via the legal system) that cannot be easily altered ex post. In contrast, policymaking is thought to be much more flexible.

An alternative, two-period formulation of the model would stipulate individuals allocating their first period income between a formal and an informal sector, which differ by their rates of return in generating second period income. In this variation, policy choices would have determined the allocation between the two sectors, whereas here the focus is on productive effort inducement. The two perspectives generate similar insights; again, for the sake of simplicity we present herein the one period version.

\section{Direct policy choices}

While our crucial assumption is that there is no possibility to credibly commit to policies, as a benchmark for the equilibrium analysis below we first explore the case where policy choices can be made directly, without resorting to a centralization regime. We will assume non-democracy here and, for concreteness, that the randomly chosen ruler originates in region 1. As a first observation, it should be clear that, if the ruler is unable to commit to policies prior to the individuals making their effort choices, then he will set $\mathrm{p}_{1}=\mathrm{p}_{2}=\pi_{1}=0$, and so $\delta_{1}=\Delta=0$, as these choices will both reduce regional policy distance and the distance 
between the ruler's ideal and actual policies to a minimum. Let's then consider the possibility of a policy commitment.

Utility maximization with respect to efforts yields the first order conditions:

$$
-e_{i}+(1-t) f\left(\delta_{j}\right)=0
$$

implying that the anticipated effort levels, hence, income levels, are:

$$
e_{i j}=(1-t) f\left(\delta_{j}\right)
$$

and the amount of the public good is

$$
G=\operatorname{tg}(\Delta)(1-t)\left[f\left(\delta_{1}\right)+f\left(\delta_{2}\right)\right] / 2
$$

The ruler's anticipated utility then is, after substitutions,

$$
\mathrm{U}_{\mathrm{i} 1}=-\mathrm{e}_{\mathrm{i} 1}^{2} / 2+(1-\mathrm{t}) \mathrm{e}_{\mathrm{i} 1} \mathrm{f}\left(\delta_{1}\right)+\operatorname{tg}(\Delta)(1-\mathrm{t})\left[\mathrm{f}\left(\delta_{1}\right)+\mathrm{f}\left(\delta_{2}\right)\right] / 2
$$

where $e_{i 1}=(1-t) f\left(\delta_{1}\right)$, from $(5)$.

Using the envelope theorem, the first order conditions with respect to policies are: ${ }^{7}$

$$
\partial \mathrm{U}_{\mathrm{i} 1} / \partial \mathrm{p}_{1}=(1-\mathrm{t}) \mathrm{e}_{\mathrm{i} 1} \mathrm{f}^{\prime}\left(\delta_{1}\right)+\mathrm{t}(1-\mathrm{t})\left[-\mathrm{g}^{\prime}(\Delta)\left(\mathrm{f}\left(\delta_{1}\right)+\mathrm{f}\left(\delta_{2}\right)\right)+\mathrm{f}^{\prime}\left(\delta_{1}\right) \mathrm{g}(\Delta)\right] / 2 \leq 0
$$

\footnotetext{
${ }^{7}$ Clearly, $\mathrm{p}_{1}<\mathrm{p}_{2}$, so the only corner solution to be considered is where $\mathrm{p}_{1}=0, \mathrm{p}_{2}=1$. We will assume that $\mathrm{p}_{2}<1$ holds.
} 
$\partial \mathrm{U}_{\mathrm{i} 1} / \partial \mathrm{p}_{2}=\mathrm{g}^{\prime}(\Delta)\left(\mathrm{f}\left(\delta_{1}\right)+\mathrm{f}\left(\delta_{2}\right)\right)-\mathrm{f}^{\prime}\left(\delta_{2}\right) \mathrm{g}(\Delta)=0$

The conditions (8) imply that $\mathrm{p}_{1}=0$, so that with policy commitment, the ruler sets her region's policy to the ideal one and adjusts the other regions' policy to optimally represent the tradeoff between lowering the interregional policy distance and inducing effort incentives for region 2's residents. Note that this outcome differs from the one where policy commitment is not possible, $\mathrm{p}_{1}=\mathrm{p}_{2}=\pi_{1}=0$. This illustrates the point that, without policy commitment there is a hold up problem, whereby region 2's policy is set too far away from local resident's preferences, resulting in inefficient effort choices (region 2's residents reducing their efforts).

It is interest to compare for future reference this outcome to that obtained under decentralization whereby the two regions choose their policies independently. Region 1's policy then maximizes (7), leading to the first order condition given by (8a), whereas region 2's policy maximizes

$$
\mathrm{U}_{\mathrm{i} 2}=-\mathrm{e}_{\mathrm{i} 2}{ }^{2} / 2+(1-\mathrm{t}) \mathrm{e}_{\mathrm{i} 2} \mathrm{f}\left(\delta_{2}\right)+\operatorname{tg}(\Delta)(1-\mathrm{t})\left[\mathrm{f}\left(\delta_{1}\right)+\mathrm{f}\left(\delta_{2}\right)\right] / 2
$$

and is given by

$$
\partial \mathrm{U}_{\mathrm{i} 2} / \partial \mathrm{p}_{2}=(1-\mathrm{t}) \mathrm{e}_{\mathrm{i}} \mathrm{f}^{\prime}\left(\delta_{2}\right)+\mathrm{t}(1-\mathrm{t})\left[-\mathrm{g}^{\prime}(\Delta)\left(\mathrm{f}\left(\delta_{1}\right)+\mathrm{f}\left(\delta_{2}\right)\right)+\mathrm{f}^{\prime}\left(\delta_{2}\right) \mathrm{g}(\Delta)\right] / 2 \geq 0
$$

Clearly, decentralization results in symmetric policy choices, so that $\delta_{1}=\delta_{2}$. 
It is also obvious that the ruler finds the decentralization outcome inferior relative to the above direct policy choices, whereby he optimally chooses policies for both regions.

We, therefore, have

Proposition 1. Under direct commitment to policy choices, the ruler always prefers centralization.

This is a benchmark result that the following analysis should be compared to. Not surprisingly, with policy commitment, the ruler prefers a centralized regime - which enables him to exercise power when choosing policies. It is against this background that we now turn to explore the role of decentralization as a commitment on the ruler's part to ensure that ex post policy choices will induce a higher individual effort.

\section{Decentralization as a commitment}

\subsection{Non-democracy}


We now turn to our main analysis, proceeding backwards. In the last stage, policy choices are made. Under centralization, with the ruler setting the policies, $\mathrm{p}_{1}=\mathrm{p}_{2}=0$, so that $\delta_{1}=\Delta$ $=0$, and $\delta_{2}=1$. Comparing with the policy commitment outcome, we observe that, while region 1's policy is the same, region 2's policy is positive in that case, so that the resulting policy polarization is positive as well, whereas here policies are uniform. The reason for this is that, with commitment, the ruler takes into account the adverse effect of moving region 2's policy away from its preferred one on the equilibrium effort of that region's residents; this consideration is absent when no policy commitment can be made.

Under decentralization, policies are independently chosen by the regions to maximize the respective residents' utilities $-\mathrm{e}_{\mathrm{i}}^{2} / 2+(1-\mathrm{t}) \mathrm{e}_{\mathrm{i}} \mathrm{f}\left(\delta_{\mathrm{j}}\right)+\mathrm{t} \int y_{i} d i \mathrm{~g}(\Delta)$. The first order conditions are ${ }^{8}$

$$
\begin{aligned}
& (1-\mathrm{t}) \mathrm{e}_{\mathrm{i} 1} \mathrm{f}^{\prime}\left(\delta_{1}\right)-\mathrm{t} \int y_{i} d i \mathrm{~g}^{\prime}(\Delta)=0 \\
& -(1-\mathrm{t}) \mathrm{e}_{\mathrm{i} 2} \mathrm{f}^{\prime}\left(\delta_{2}\right)+\mathrm{t} \int y_{i} d i \mathrm{~g}^{\prime}(\Delta)=0
\end{aligned}
$$

Differentiation of (10) reveals that $\mathrm{p}_{1}$ increases (and $\mathrm{p}_{2}$ decreases) in $\mathrm{t}$, implying, in turn, that policy polarization decreases - and equilibrium policies become further removed from the regions' ideal ones - the larger is the tax rate used to finance the public good. The reason for

\footnotetext{
${ }^{8}$ It will be clear that efforts, hence incomes within a region are identical. Also, clearly $\delta_{1}<1 / 2$.
} 
this is that a higher tax rate reduces the marginal value of private consumption, while ultimately increasing the consumption value of the public good. These factors make policy polarization relatively more detrimental.

We then have

Lemma 1. The larger is the exogenous tax rate the larger is the distance between the decentralization policies and the ideal ones.

The equilibrium efforts (and incomes) then are given as follows:

$e^{d}=y^{d}=(1-t) f\left(\delta_{1}\right) ; e_{i}^{c}=y_{i}^{c}=(1-t) f(0), i$ is from region 1 , and $e_{i}^{c}=y_{i}^{c}=(1-t) f(1), i$ is from region 2

(Note that $\delta_{1}=\delta_{2}$, implying that policies are symmetric, $\mathrm{p}_{1}=1-\mathrm{p}_{2}$; hence, $\Delta=1-2 \delta_{1}$.) As $\delta_{1}<1 / 2$, our assumptions on $\mathrm{f}$ directly lead to the following result, obtained by comparing the equilibrium efforts in (11):

Proposition 2. Equilibrium efforts under decentralization are smaller than under centralization in region 1 and larger than in region 2. Aggregate effort, hence taxable income and the amount of the public good are larger under decentralization. 
These derivations enable us to write the utility level of region 1's residents under each of the two regimes:

$$
\mathrm{U}_{\mathrm{i} 1}{ }^{\mathrm{d}}=-\left[(1-\mathrm{t}) \mathrm{f}\left(\delta_{1}\right)\right]^{2} / 2+(1-\mathrm{t})^{2} \mathrm{f}\left(\delta_{1}\right)+\mathrm{t}(1-\mathrm{t}) \mathrm{f}\left(\delta_{1}\right) \mathrm{g}\left(1-2 \delta_{1}\right)
$$

and

$$
\begin{aligned}
& U_{i 1}{ }^{c}=-[(1-t) f(0)]^{2} / 2+(1-t)^{2} f(0)+t\{[(1-t) f(0)+(1-t) f(1)] / 2\} g(0)= \\
& -(1-t)^{2} / 2+(1-t)^{2}+t(1-t) / 2=(1-t) / 2
\end{aligned}
$$

where normalizations of $\mathrm{f}$ and $\mathrm{g}$ have been used. Differentiating (12) and utilizing (10) and (11), we observe that it decreases with respect to $\delta_{1}-$ utility levels decrease because induced efforts are smaller the more selected policies are removed from regional ideals.

As the ruler comes from region 1, he will make the determination as to the centralization regime, based on the welfare differential

$\mathrm{U}_{\mathrm{i} 1}{ }^{\mathrm{d}}-\mathrm{U}_{\mathrm{i} 1}{ }^{\mathrm{c}}=-\left[(1-\mathrm{t}) \mathrm{f}\left(\delta_{1}\right)\right]^{2} / 2+(1-\mathrm{t})^{2} \mathrm{f}\left(\delta_{1}\right)+\mathrm{t}(1-\mathrm{t}) \mathrm{f}\left(\delta_{1}\right) \mathrm{g}\left(1-2 \delta_{1}\right)-\quad(1-\mathrm{t}) / 2$

which decreases in $\delta_{1}$. When $\delta_{1}=0$, the above differential is clearly negative, whereas when $\delta_{1}=1 / 2$, it is positive.

We can, therefore, summarize: 
Proposition 3. The ruler may favor ex ante decentralization. This is the outcome when the equilibrium policy choices under the decentralization regime are sufficiently close to the respective regions' ideal ones, ensuring a larger aggregate effort ex post.

Now, as policies under decentralization are determined, in particular, by the exogenous tax rate and recalling Lemma 1, we obtain the following:

Corollary. The larger is the tax rate the less advantageous decentralization is.

\subsection{Democracy}

Recall that under democracy, the regime decision must be made first, upon which the political leader is randomly drawn to implement policies after the individuals have made their effort choices. Again, we explore the subgame perfect equilibrium.

If decentralization is chosen, then the equilibrium policy choices are given by (10). In the case of centralization, depending on the leader's identity, his policy choices will either be $\mathrm{p}_{1}=\mathrm{p}_{2}=0$ (if the leader is known to have originated from region 1 ), or $\mathrm{p}_{1}=\mathrm{p}_{2}=1$ (if the leader is from region 2). In the former case, the individual efforts (and incomes) can be seen to be

$e_{i}^{c}=y_{i}^{c}=(1-t) f(0), i$ is from region 1 , and $e_{i}^{c}=y_{i}^{c}=(1-t) f(1), i$ is from region 2 ; 
and in the latter case,

$$
e_{i}^{c}=y_{i}^{c}=(1-t) f(1), i \text { is from region } 1 \text {, and } e_{i}^{c}=y_{i}^{c}=(1-t) f(0), i \text { is from region } 2
$$

It then follows that the amount of aggregate taxable income, $(\mathrm{f}(1)+\mathrm{f}(0)) / 2$, and the amount of the public good, $t[(f(1)+f(0)) / 2] g(1)=0$, both smaller than the respective amounts under nondemocracy.

An individual's expected utility then is

$U_{i}^{c}=-\left\{[(1-t) f(0)]^{2} / 2+[(1-t) f(1)]^{2} / 2\right\} / 2+(1-t)[f(0)+f(1)] / 2=$

$-(1-t)^{2} / 2+(1-t) / 2$

smaller than the utility of the ruler's region under non-democracy, (13). It then follows that centralization is a less favorable outcome than decentralization under democracy.

Or, summarizing somewhat differently,

Proposition 4. Decentralization constitutes an equilibrium outcome under non-democracy only if it does so under democracy. 
The above view of a democracy under centralization, by letting a randomly elected leader impose her preferred policies, leaves scope for potential gains, which can in principle be realized, depending on the nature of the legislative bargaining process. In the appendix, therefore, one such possibility is explored.

\subsection{Discussion of evidence}

Several pieces of empirical evidence are consistent with the model's predictions. One set of predictions is that decentralization leads to more efficient outcomes at the local level. Various countries' experiences testify that this is, indeed, the case. For example, Faquet, 2004, explores the effects of a substantial decentralization move that took place in Bolivia in 1990s. As a result of this move, local authorities acquired a significantly larger amount of resources than before to spend on local needs. Faquet, 2004, finds that this resulted in much improved investment in human capital and social services at the local level. Galasso and Ravallion, 2005, find that decentralization improved pro-poor targeting in Bangladesh. Zhang et al., 2004, explore the consequences of a move toward village autonomy in China in 1980-90s. This is an interesting for us case, where the devolution of power was undertaken in a non-democratic context. The finding is that this led to better public services. Jin et al., 2006, likewise explore the consequences of governance reforms in China, focusing on a 
somewhat earlier period, of 1980s, referred to as "eating in separate kitchen". 9 This is when, while some decentralization already took place, local elections had not been introduced, and local political leaders were appointed by the central government. ${ }^{10}$ Still, the authors find improved outcomes resulting from the reform. Specifically, a much larger fraction of tax revenues was locally retained, and there was a measurable improvement in the functioning of state owned enterprises, as well as faster development of non-state ones. With the focus on a developed economy, Barankay and Lockwood, 2007, find that decentralization improved education outcomes in Switzerland.

Also of empirical interest is the result that links decentralization to democracy. Empirical support for it is to be found in Panizza, 1999. There, democracy is detected to be correlated with fiscal decentralization across countries, after controlling for countries' characteristics, such as their size and ethnic fractionalization. As pointed out in Panizza, 1999, these results can provide insights on the decentralization process that swept - and are still sweeping - parts of East Europe after the end of the Cold War.

\footnotetext{
${ }^{9}$ Envisioned already by Chairman Mao: "The central authorities should take care to give scope to the initiative of provinces and municipalities, and the latter in their turn should do the same for the prefectures, counties, districts and townships; in neither case should the lower levels be put in a strait-jacket" (Mao, 1977).

${ }^{10}$ Local elections were introduced subsequently, in 1990s.
} 


\section{Conclusion}

This paper's main objective has been to present an analytical framework that would rationalize voluntary moves toward government decentralization, even in non-democratic settings, as exemplified by China's 1980s reforms. The presented point of view relies on second generation models of fiscal federalism and views decentralization as a commitment device ensuring that policy choices reflect more accurately local preferences; in the absence of credible commitments, centralization cannot guarantee that. As a consequence, decentralization should lead to more efficient effort levels, larger state revenues and public good provision.

The theory developed in this paper is, of course, just one of several possibilities to rationalize voluntary devolution of central government's responsibilities. Some alternative explanations include increasing citizens' satisfaction by moving government "close to the people", and enhancing opportunities for local monitoring of politicians and punishing them for poor choices or performance. While the discussed empirical evidence is consistent with the paper's arguments, further evidence is needed to distinguish between the various alternative explanations behind decentralization processes. 


\section{APPENDIX: Legislative bargaining under centralization}

We herein assume an alternative frictionless bargaining process under centralization, whereby total surplus is being maximized when policy choices are made ex ante.

We first consider, as a benchmark, direct policy choices with commitment. Equations (5) and (6) determine the individual efforts and the amount of the public good, leading to respective utility levels of the residents of region 1 and region 2:

$\mathrm{U}_{\mathrm{i} 1}=-\mathrm{e}_{\mathrm{i} 1}{ }^{2} / 2+(1-\mathrm{t}) \mathrm{e}_{\mathrm{i} 1} \mathrm{f}\left(\delta_{1}\right)+\operatorname{tg}(\Delta)(1-\mathrm{t})\left[\mathrm{f}\left(\delta_{1}\right)+\mathrm{f}\left(\delta_{2}\right)\right] / 2$

and

$\mathrm{U}_{\mathrm{i} 2}=-\mathrm{e}_{\mathrm{i} 2}^{2} / 2+(1-\mathrm{t}) \mathrm{e}_{\mathrm{i} 2} \mathrm{f}\left(\delta_{2}\right)+\operatorname{tg}(\Delta)(1-\mathrm{t})\left[\mathrm{f}\left(\delta_{1}\right)+\mathrm{f}\left(\delta_{2}\right)\right] / 2$

where $e_{i j}=(1-t) f\left(\delta_{j}\right), j=1,2$.

Under cooperative legislative bargaining, policy choices are made so as to maximize their sum total.

The first order condition with respect to the policies $\mathrm{p}_{1}$ and $\mathrm{p}_{2}$, respectively, are:

$$
\begin{aligned}
& \mathrm{e}_{\mathrm{i} 1} \mathrm{f}^{\prime}\left(\delta_{1}\right)+\mathrm{t}\left[\mathrm{f}^{\prime}\left(\delta_{1}\right) \mathrm{g}(\Delta)-\mathrm{g}^{\prime}(\Delta)\left(\mathrm{f}\left(\delta_{1}\right)+\mathrm{f}\left(\delta_{2}\right)\right)\right]=0 \\
& \mathrm{e}_{\mathrm{i} 2} \mathrm{f}^{\prime}\left(\delta_{2}\right)+\mathrm{t}\left[-\mathrm{f}^{\prime}\left(\delta_{2}\right) \mathrm{g}(\Delta)+\mathrm{g}^{\prime}(\Delta)\left(\mathrm{f}\left(\delta_{1}\right)+\mathrm{f}\left(\delta_{2}\right)\right)\right]=0
\end{aligned}
$$


It follows that $\delta_{1}=\delta_{2}$, and we can write, after substituting the equilibrium efforts:

$(1-\mathrm{t}) \mathrm{f}\left(\delta_{1}\right) \mathrm{f}^{\prime}\left(\delta_{1}\right)+\mathrm{t}\left[\mathrm{f}^{\prime}\left(\delta_{1}\right) \mathrm{g}\left(1-2 \delta_{1}\right)-2 \mathrm{~g}^{\prime}\left(1-2 \delta_{1}\right) \mathrm{f}\left(\delta_{1}\right)\right]=0$

Thus chosen policies maximize aggregate welfare and leave no surplus out.

In contrast, consider the centralization regime, where policies are chosen at the last stage by the cooperative legislature. The respective first order conditions then are as follows:

$\mathrm{e}_{\mathrm{i} 1} \mathrm{f}^{\prime}\left(\delta_{1}\right)-\operatorname{tg}^{\prime}(\Delta)\left(\mathrm{f}\left(\delta_{1}\right)+\mathrm{f}\left(\delta_{2}\right)\right)=0$

$\mathrm{e}_{\mathrm{i} 2} \mathrm{f}^{\prime}\left(\delta_{2}\right)-\operatorname{tg}^{\prime}(\Delta)\left(\mathrm{f}\left(\delta_{1}\right)+\mathrm{f}\left(\delta_{2}\right)\right)=0$

Anticipating these choices, the equilibrium effort levels are $e_{i j}=(1-t) f\left(\delta_{j}\right), j=1,2$, substitution of which yields:

$$
\begin{aligned}
& (1-t) f\left(\delta_{1}\right) f^{\prime}\left(\delta_{1}\right)-\operatorname{tg}^{\prime}(\Delta)\left(f\left(\delta_{1}\right)+f^{\prime}\left(\delta_{2}\right)\right)=0 \\
& -(1-t) f^{\prime}\left(\delta_{2}\right) f^{\prime}\left(\delta_{2}\right)+\operatorname{tg}^{\prime}(\Delta)\left(f\left(\delta_{1}\right)+f\left(\delta_{2}\right)\right)=0
\end{aligned}
$$

Again $\delta_{1}=\delta_{2}$, and we re-write the first order condition as follows:

$$
(1-t) f^{\prime}\left(\delta_{1}\right)-2 \operatorname{tg}^{\prime}\left(1-2 \delta_{1}\right)=0
$$


Comparing (A1) and (A2), we observe that, when policies are determined ex ante, $\delta_{1}$ is smaller than when they are determined under centralization ex post - implying also that policy polarization is smaller in the former case. The reason for this is clear: when policies can be committed ahead of individual effort choices, their effect on these choices is taken into consideration, resulting in policies being relatively close to the regions' ideals.

We can also compare these policy choices with those under decentralization, given by (10). To this end, it will be convenient to re-write (10) as

$$
(1-\mathrm{t}) \mathrm{f}^{\prime}\left(\delta_{1}\right)-\mathrm{tg}^{\prime}\left(1-2 \delta_{1}\right)=0
$$

Comparing (A3) and (A2), we observe that $\delta_{1}$ is larger, implying a higher degree of policy homogenization, under centralization. This, of course, is not surprising, as centralization internalizes spillovers involved in policy coordination that decentralization fails to internalize. Note, however, that the implication of this result is that the amount of effort, which is inversely related to policy homogenization, is higher under decentralization.

Summing up,

Proposition A1. Centralized cooperative bargaining leads to excessive policy homogenization and a lower aggregate effort both relative to the welfare maximizing benchmark, whereby policies can be precommited, and relative to decentralization. 
The comparison between centralization and decentralization in this case depends on the properties of the $\mathrm{f}$ and $\mathrm{g}$ function, and its outcome is hard to characterize in general.

\section{REFERENCES}

Acemoglu D. and J. Robinson (2008), "Persistence of Power, Elites and Institutions," American Economic Review, 98:1, 267-293.

Albornoz, F. and A. Cabrales, 2003, "Decentralization, political competition and corruption," Journal of Development Economics, 105, 103-111.

Barankay, I. and B. Lockwood, 2007, "Decentralization and the productive efficiency of government: Evidence from Swiss cantons," Journal of Public Economics, 1197-1218

Bardhan, P., 2002, "Decentralization of Governance and Development," Journal of Economic Perspectives, 16, 185-205.

Bardhan, P. and D. Mookherjee, 2005, "Decentralizing Antipoverty Program Delivery in Developing Countries," Journal of Public Economics.

Bardhan, P. and D. Mookherjee, 2006, "Decentralization and Accountability in Infrastructure Delivery in Developing Countries," Economic Journal.

Bertocchi, G. and M. Spagat, 2001, "The Politics of Cooptation", Journal of Comparative Economics 29, 591-607. 
Besley, T., 2006. Principled agents? The political economy of good government. New York: Oxford University Press.

Besley, T., V. Rao, and R. Pande. 2005, "Participatory democracy in action: Survey evidence from south India," Journal of the European Economic Association 3 (2-3): 648657.

Cai, H. and D. Treisman, 2004, "State Corroding Federalism," Journal of Public Economics, 88, 819-43.

Cervellati, M., P. Fortunato, and U. Sunde, 2008, "Hobbes to Rousseau: Inequality, Institutions and Development”, Economic Journal, 118(531), 1354-1384, 2008.

De Mello, L. and M. Barenstein, 2001, "Fiscal decentralization and governance: A cross country analysis," IMF WP 01/71.

Faquet, J.-P., 2004, "Does decentralization increase government responsiveness to local needs?: Evidence from Bolivia,” Journal of Public Economics, 88, 867-893.

Galasso, E. and M. Ravallion, 2005. "Decentralized targeting of an antipoverty program," Journal of Public Economics, 89(4), pages 705-727.

Gradstein, M., 2007, "Inequality, Democracy, and the Protection of Property Rights," 2007, Economic Journal, 117, 252-269.

Gradstein, M., 2008, "Institutional Traps and Economic Growth," International Economic Review, 49, 1043-1066.

Hatfield, J.W. and G. Padró i Miquel, 2012, “A Political Economy Theory of Partial Decentralization," Journal of European Economic Association, 10, 605-633.

Jin, H., Qian, Y., and B. Weingast, 2006, "Regional decentralization and fiscal incentives: Federalism, Chinese style," Journal of Public Economics, 1719-1742.

Joanis, M., 2013, "Shared Accountability and Partial Decentralization in Local Public Good Provision," Journal of Development Economics, forthcoming.

Keefer, P. 2007, "Clientelism, credibility, and the policy choices of young democracies," American Journal of Political Science 51 (4): 804-821. 
Khemani, S., 2007, "Does Delegation of Fiscal Policy to an Independent Agency Make a Difference? Evidence from Intergovernmental Transfers in India," Journal of Development Economics, 82(2): 464-484.

Mao, Zedong (1977), Selected Works of Mao Zedong, Volume 5. Beijing: People's Press.

Martinez-Vazquez, J., and McNab, R. (2003). "Fiscal Decentralization and Economic Growth," World Development 31(9), pp. 1597-1616.

Oates, Wallace. 1972. Fiscal Federalism. New York: Harcourt Brace Jovanovich.

Panizza, U., 1999, "On the determinants of fiscal centralization: Theory and evidence," Journal of Public Economics 74 (1999) 97-139

Qian, Y. and Weingast, B.R., 1997. "Federalism as a commitment to preserving market incentives," Journal of Economic Perspectives 11 (4), 83-92.

Seabright, P., 1996, "Accountability and decentralization in government: An incomplete contracts model," European Economic Review, 40, 61-89.

Tiebout, Charles M. 1956. "A Pure Theory of Local Expenditures." Journal of Political Economy, 64:5, pp. 416-24.

Weingast, B.R., "The economic role of political institutions: Market preserving federalism and economic development," Journal of Law, Economics, and Organization.

World Development Report, 2004,Washington DC: World Bank and Oxford University Press.

Zhang, X., Fana, S., Zhang, L., and J. Huang, 2004, "Local governance and public goods provision in rural China," Journal of Public Economics, 2857-2871. 